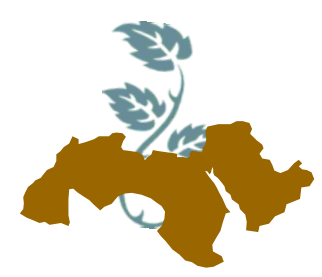

Arab Univ.

\title{
AN EXPERT SYSTEM FOR SELECTING THE TECHNICAL SPECIFICA- TIONS OF DRIP IRRIGATION CONTROL UNIT
}

\author{
Samar, A. Ragab ${ }^{1}$; A.M. El-Gindy ${ }^{2}$; Y.E. Arafa ${ }^{2}$ and Maybelle S. Gaballah ${ }^{2}$
}

1- Water Relations and Field Irrigation Dept., National Research Centre, Giza, Egypt.

2- Agric. Eng. Dept., Fac. of Agric., Ain Shams Univ., Cairo, Egypt.

Keywords: Expert systems, control head unit components, technical specifications and drip irrigation

\section{ABSTRACT}

The good design of irrigation system is one of the main steps of extent the life of the irrigation system, as well as increase the cultivated crop productivity by choosing the proper components of irrigation system control head unit ( such as pump, motor, filters, main line pipe, fertilization device, and the different control unit attachements). Different types of control unit components are used according to the system conditions for irrigation of agricultural areas. It is very difficult to find an expert at desired time and desired place for choosing correct control unit which are varied in different types and models. In this study, this problem was to be tried to solve by designing of an expert system for choosing proper components of control unit in irrigation network. A rule-based program named TSDI-ES (Technical Specification of Drip Irrigation-Expert System) was coded and compiled using Microsoft visual basic 2013 language.

Generally, the expert system database obtained from commonly used all components of control unit in irrigation network in Egypt. selection of all components of control head unit in irrigation network were determined by taking into consideration the following parameters: water resource, irrigation methods, irrigation area, crop pattern, climate, soil properties, and well characteristics. Results of the investigation indicated that it is possible to use the TSDI-ES rule-based program for choosing all proper components of control head unit in drip irrigation network such as pump, filtration unit, fertilizers devices, and flow, pressure measuerement and control devices.

\section{INTRODUCTION}

Most of Egyptians economy depends on agriculture. therefore, Egypt needs to increase the agricultural production as much as possible. This increase can be achieved using a new technology in irrigation. The development of agriculture in Egypt depends on the horizontal expansion in deserts which uses the pressurized irrigation systems such as drip irrigation system to save each water drop for more crop. The cultivated area in Egypt depends on irrigation under available technology. Kabany (2003) said that the applications of ES in agriculture were developed to give the agriculture high technology or techniques for greater profitability.

There are different types of control unit components which used for irrigation. Selection of these components depends on farm conditions. These components such as pump, filters, injection equipment, valves, protection equipment, have different and various models and classifications such as pumps can be submersible pump, centrifugal pump and deep well pump, and filters can be disk, screen and media filter and the filtration devices can be positive displacement pumps, venturi and pressure differentia tank. and so on for all components of drip irrigation system network

The selection of the appropriate and correct control unit components for the farm is very hard due to various planning factors such as type of land, irrigation method, plant type and water source. For these reasons, the selection of pump, filters and other components of the control unit 
used in drip irrigation system. An expert is needed for the correct selection, so it would be more appropriate to develop an expert system for this task. Awady et al (2002) reported some criteria concerning on the selection processes of irrigation system in certain situations depend on farm resources (soil, water, crop, labors, energy and costs). Each irrigation system was given a source for every resource item. Virtual scores were allotted to different choice according to different qualifiers. The assumption was based on experience and judgments of the authors and domain expert.

The agricultural expert system originated in China in 1980s, and it transforms the expertise of agriculture to computer program to spread expertise and experience. It is an effective tool for spreading agriculture knowledge and technology Mcknion and Lemmon. (1985). an expert system is defined as a computer program that is designed to modulate the problem solving ability of a human expert by using artificial intelligence. Artificial intelligence is a new science that deals with representation and use of knowledge. The goal of artificial intelligence is to make computers more useful for reasoning, planning and communicating with humans. Rogers et al (2003) usually there are several versions of each component. The major factors that should be considered when selecting each component are listed under considerations. Make sure the characteristics of your site and system are specifically addressed in your SDI system design. Arafa (2004) built an expert system called LIS-ES for application priorities of localized irrigation systems under diverse conditions of the newly reclaimed lands in the Northwestern of Egypt. They speculated that surface drip irrigation system has the majority for application under different soils and crop patterns. Meanwhile, bubbler and low-head-gravity-flow bubbler irrigation systems have the advantages for application under orchard crops, whenever, irrigation water are low in quality and soils are affected by both salinity and high levels of Calcium Carbonate fraction. Patterson (2007) stated that an expert system is an interactive-based decision tool that uses both facts and heuristics to solve difficult decision making problems, based on knowledge acquired from an expert. Phocaides (2007) reported that all the components of the head control of the system must be determined, i.e. shut-off valves, check valve, air valve, fertilizer injector, filters, pressure regulators, etc. In addition, all the auxiliary fittings must be included, such as the pipe pieces, hoses and fittings needed to assemble the unit, and the pressure gauges and other small devices required. Selflek and Carmen
(2010) said that expert systems can be an alternative choice for the private sector due to difficulties encountered in finding the expert person at all times and everywhere and high costs of expert persons. Computer programs known as expert systems are believed to be the best fitting method for the solution of complex problems like pump selection.

The aim of this study is to develop and validate expert system for selecting the control unit components belonging to different firms. This expert system performs the task of selection of control unit components like an expert and make it possible to compare selected parts that belong to different firms according to their technical specifications

\section{MATERIALS AND METHODS}

In order to determine the technical specifications of control head unit in this study, several meetings were held with pump, and different irrigation system components dealers and manufactures that have substantial sales in Egypt. These data were used to establish the database.

A rule-based program named TSDI-ES (Technical Specifications of Drip Irrigation Control UnitExpert System) was coded and compiled using Microsoft visual basic 2013 language which represents a part of Microsoft Visual Studio Express 2013 for Windows desktop package. The schematic overview showing the key input and output processes and main computational steps needed for the TSDI-ES rule-based program. The following steps outline how the TSDI-ES program was built.

A graphic user interface (GUI) is designed to have a clear and soft feel to advance easy use for both experienced users and novice, as farmers, also support them with decision-making related to select the technical specifications of drip irrigation control unit easily and precisely.

The structure of the TSDI-ES rule-based program was designed to choice the technical specifications of drip irrigation control unit. The structure of the program consisted of the following:

Figure (1) shows the TSDI-ES program's flow chart which was divided into three main parts (a) location data, (b) irrigation water data, (c) and crop data. Each part has some inputs to make the internal calculations for getting the results which will be used in choosing the technical specifications of the control head components of the drip irrigation (pump, filtration equipment, fertigation device, and other control measurement devices. 
Arab Univ.

J. Agric. Sci., Ain Shams Univ.,

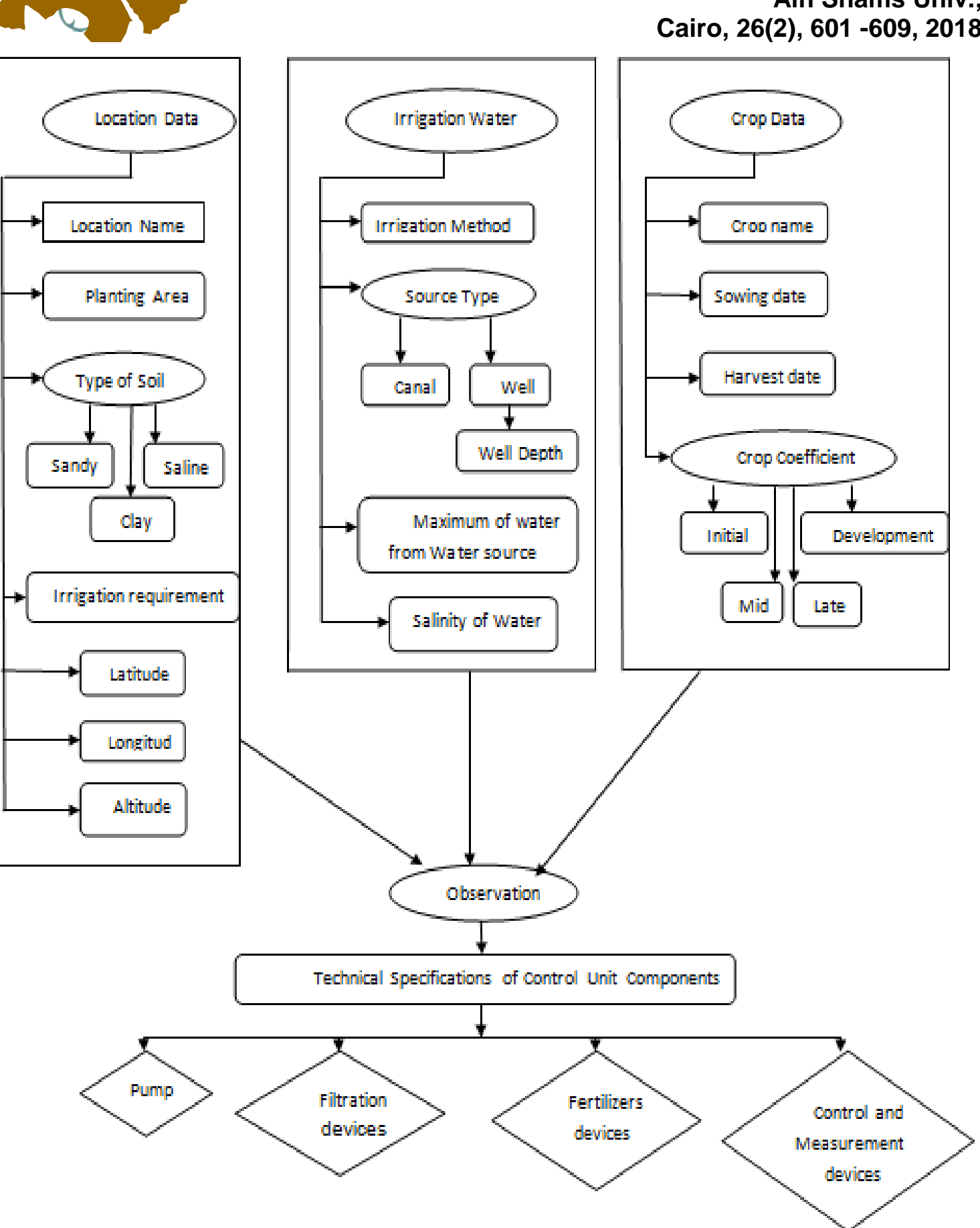

Fig. 1. Flowchart used to select the technical specifications for components of control head unit in irrigation network.

(Received 28 August, 2017)

(Revised 10 September, 2017)

(Accepted 10 September, 2017) 

Arab Univ. J. Agric. Sci., Ain Shams Univ., Cairo, 26(2), 601 -609, 2018 
The plant's pump flow rate requirement was calculated by a multiplication of the irrigation module, which is a function of various types of plants being cultivated in the region (climatic and soil properties) and the area of irrigation. Maximum water consumption of plants was taken as a basis in the calculation of the irrigation module.

Before the pump selection, the program controls, the adequacy of the water source capacity (required flow rate) and compares the required flow rate with well discharge. In a negative condition, the user is warned instantly. Then, the suitable pumps are searched out from the database according to required flow rate and total manometric head.

After the pump selection belonging to different firms, the features such as water horse power are calculated by flow rate and total manometric head. The constraints of the pump selection in the expert system are related to the database.

Selection of filters was depended on the flow rate of the chosen pump, so that the discharge of filter is more than the flow rate of the chosen pump by about $25 \%$ according to the reverse washing operations.

\section{RESULTS AND DISCUSSION}

As recorded in Table (1) for the two studied regions, the pump types were chosen from the program database, depending on the irrigation options such as the maximum required discharge, required pump discharge, and the required dynamic head of the pump. Moreover, the user could change his data according to prices of the output pumps, by changing the dynamic head.

Table 1. The outputs for choosing the pump

\begin{tabular}{|c|c|c|}
\hline $\begin{array}{c}\text { Technical } \\
\text { specifications }\end{array}$ & Region1 & Region2 \\
\hline Model & N100-250 A & N100-200B \\
Discharge $\left(\mathrm{m}^{3} / \mathrm{h}\right)$ & 247 & 180 \\
Number of pump & 3 & 4 \\
Out diameter $(\mathrm{mm})$ & 4 & 4 \\
B.H.P $(\mathrm{hp})$ & 100 & 50 \\
W.H.P $(\mathrm{hp})$ & 73 & 33.3 \\
Required engine \\
$(\mathrm{kW})$
\end{tabular}

Selection of filters was depended on the flow rate of the chosen pump, as shown in Table (2). So, the discharge of the chosen filters should be more than the flow rate of the chosen pump by about $25 \%$ according to the reverse washing operations. In the filters screen, the user can choose the type of filters only for well water resource, but for the surface irrigation water resource, he should use both types of filters (disc and/or screen + media). Generally, the two types of filters should exist for the drip irrigation system safety and to reduce the logging of emitters, as well as maximize the efficiency of the irrigation system.

Table 2. The outputs for choosing the filters

\begin{tabular}{|c|c|c|}
\hline $\begin{array}{c}\text { Technical } \\
\text { specifications }\end{array}$ & Region1 & Region2 \\
\hline $\begin{array}{c}\text { Type } \\
\text { Total } \\
\text { discharge }\left(\mathrm{m}^{3} / \mathrm{h}\right)\end{array}$ & Disk & Disk \\
Number of filters \\
$\begin{array}{c}\text { Filter } \\
\text { discharge }\left(\mathrm{m}^{3} / \mathrm{h}\right) \\
\text { Diameter(inch) } \\
\text { Filtration grade } \\
\text { (micron) }\end{array}$ & 52 & 225 \\
\hline
\end{tabular}

The next step is choosing the proper fertilizing device; was the injector equipment of fertilizers had a separate screen to make it simple and easy for the user to choose. Table (3) showed the recommended fertilizers injection equipment capacity $18 \mathrm{~L} / \mathrm{h}$ for the two studied regions and the technical specifications of venturi was presented.

Table 3. The outputs for choosing the fertigation equipment.

\begin{tabular}{|c|c|}
\hline $\begin{array}{c}\text { Type of fertigation } \\
\text { equipment }\end{array}$ & Venturi \\
\hline $\begin{array}{c}\text { Inlet/outlet connection } \\
\text { (inch) }\end{array}$ & 0.75 \\
Inlet pressure (bar) & 3 \\
Outlet pressure (bar) & 2 \\
Injection rate (I/h) & 18 \\
\hline
\end{tabular}

The following step was to choose the proper attached valves and other components of the drip 
irrigation control unit. Figure (2) showed the recommended gate valve, non-return valve, pressure relief valve, air vent, vacuum breaker, water meter, and pressure gauge diameters for the two studied regions.

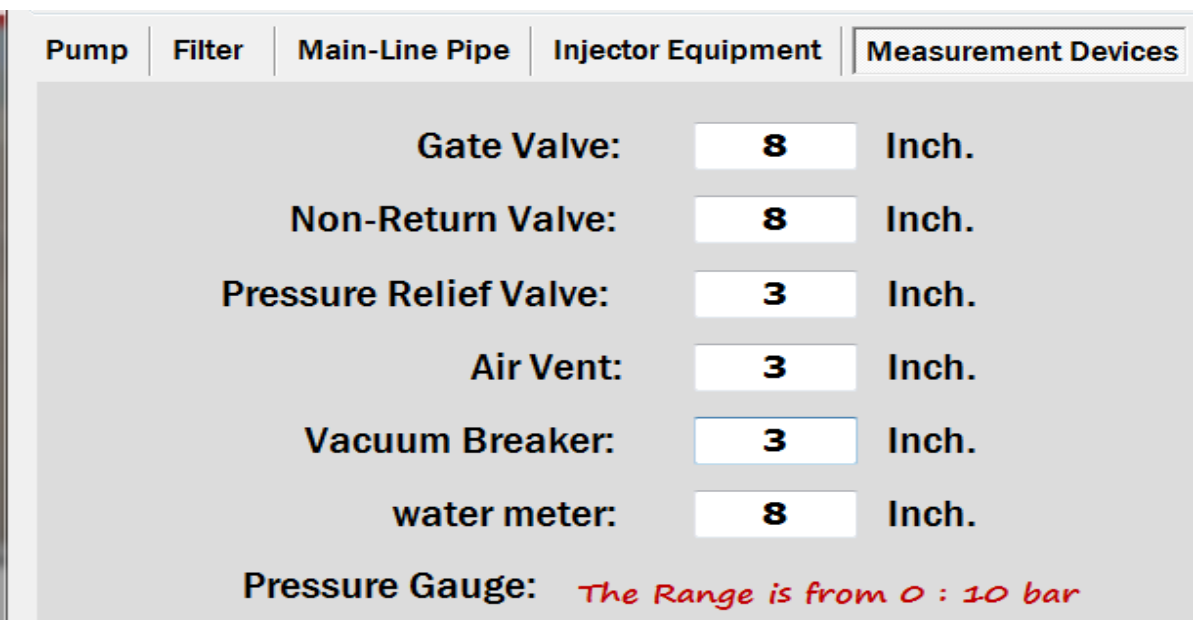

Return to Inputs

Fig. 2. The output screen for choosing the protection Equipment

\section{Expert System Verification}

Verification is like debugging, it is intended to ensure that the developed expert system does what it is intended to do. Expert systems are often computer programs. Therefore all techniques that can help develop, debug or maintain computer programs are also useful for the expert system models. Comparison with a real system is the most reliable and preferred way to validate an expert system. Assumptions, input values, output values, configurations and system behavior should all be compared with those observed in the real world. In the case of expert system, when full measurement data is available it may be possible to use tracedriven to observe the model under exactly the same conditions as the real system. By examining the calculations of TSDI-ES the programming code goes well without any errors
Validation process under the two studied regions

Two regions as two cases studies also the suggested crops for cultivation in these two regions were selected according to the 1.5 Million Fadden Project book. The Results of Irrigation requirements estimated by the TSDI-ES rule-based program were compared with those estimated by the manual calculations for each crop (Sesame, Sunflower, Sugar beet in Menia region, and olives and palm trees in Farafra region) as shown in Figures $(3,4,5,6,7)$ respectively. It could be noticed the high correlation between the TSDI-ES rule based program and the manual calculations, for that TSDI-ES gives powerful predictions for IR according to the correct inputs data of $\mathrm{ET}_{0}$. 


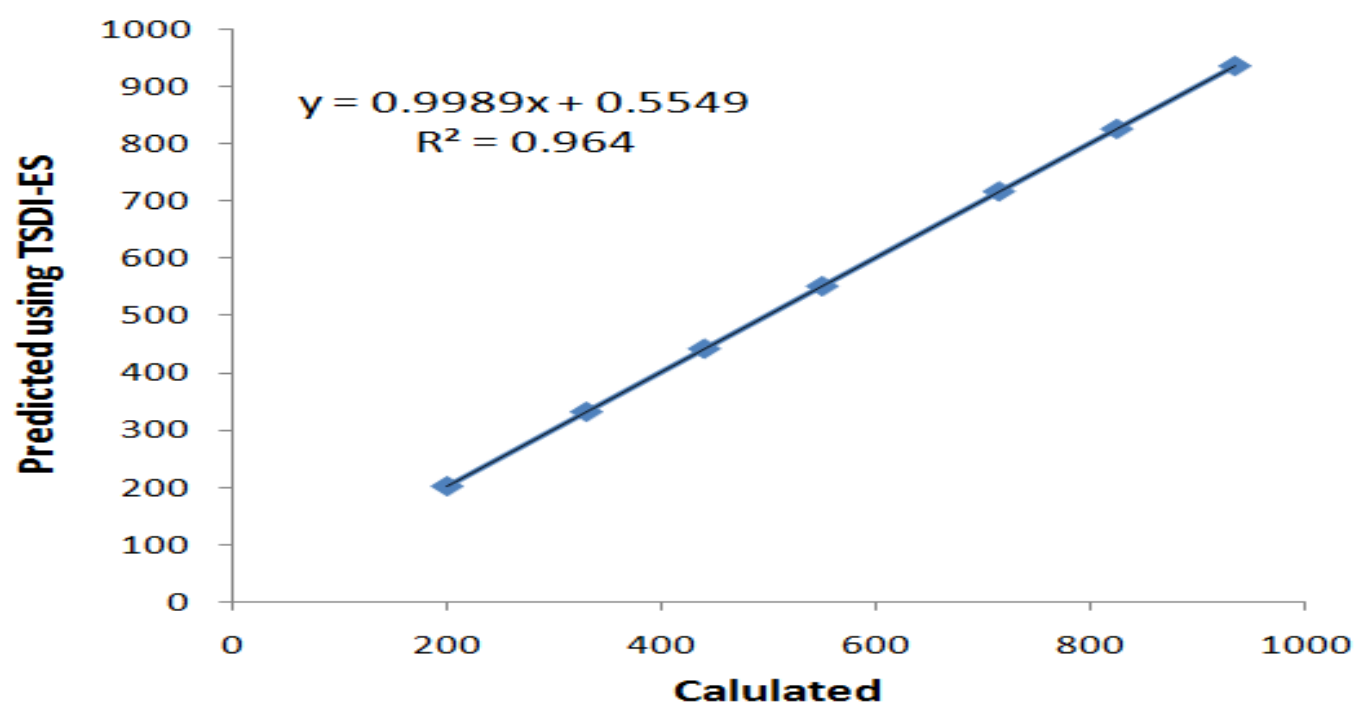

Fig. 3. Calculation of IR using the TSDI-ES Program and manual calculations for sesame in Menia region

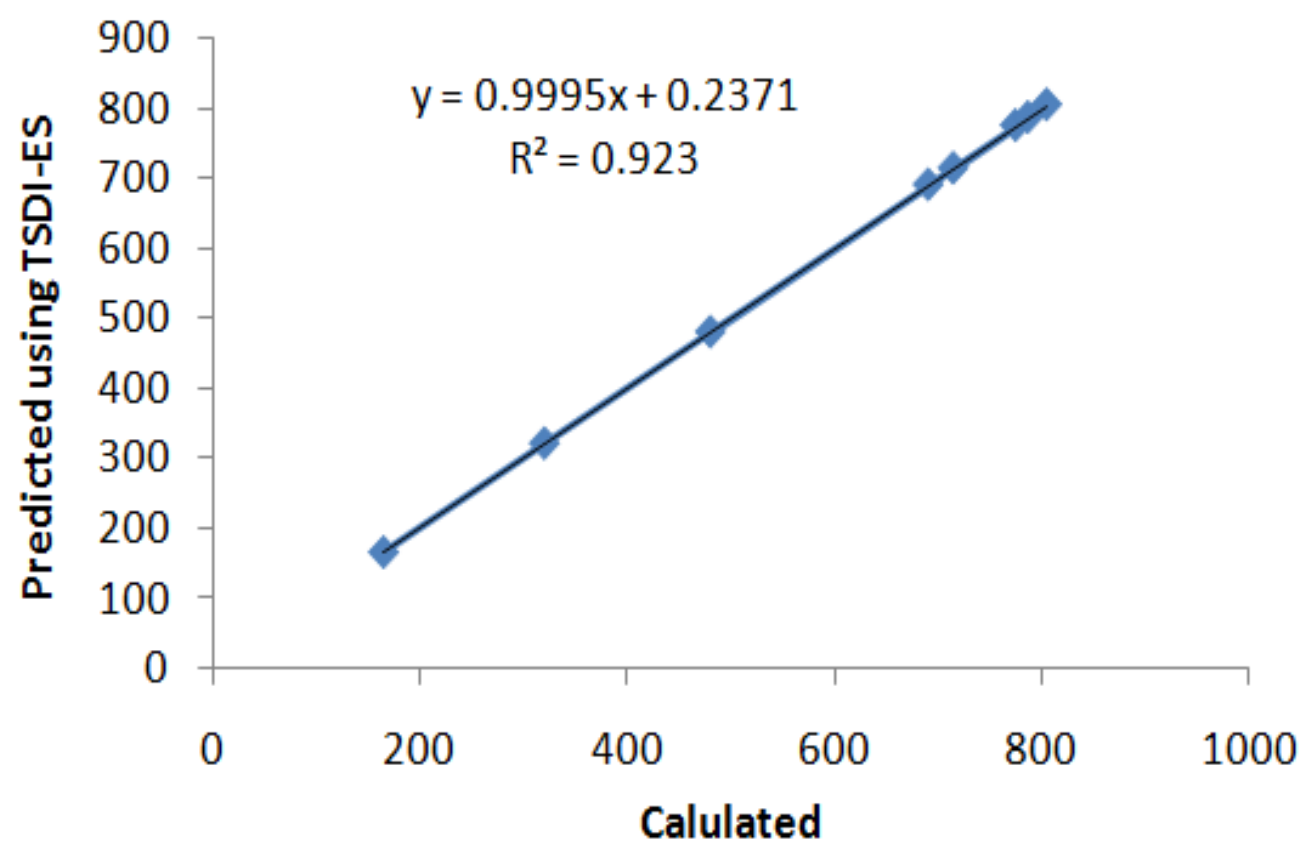

Fig. 4. Calculation of IR using the TSDI-ES Program and manual calculations for sunflower in Menia region 


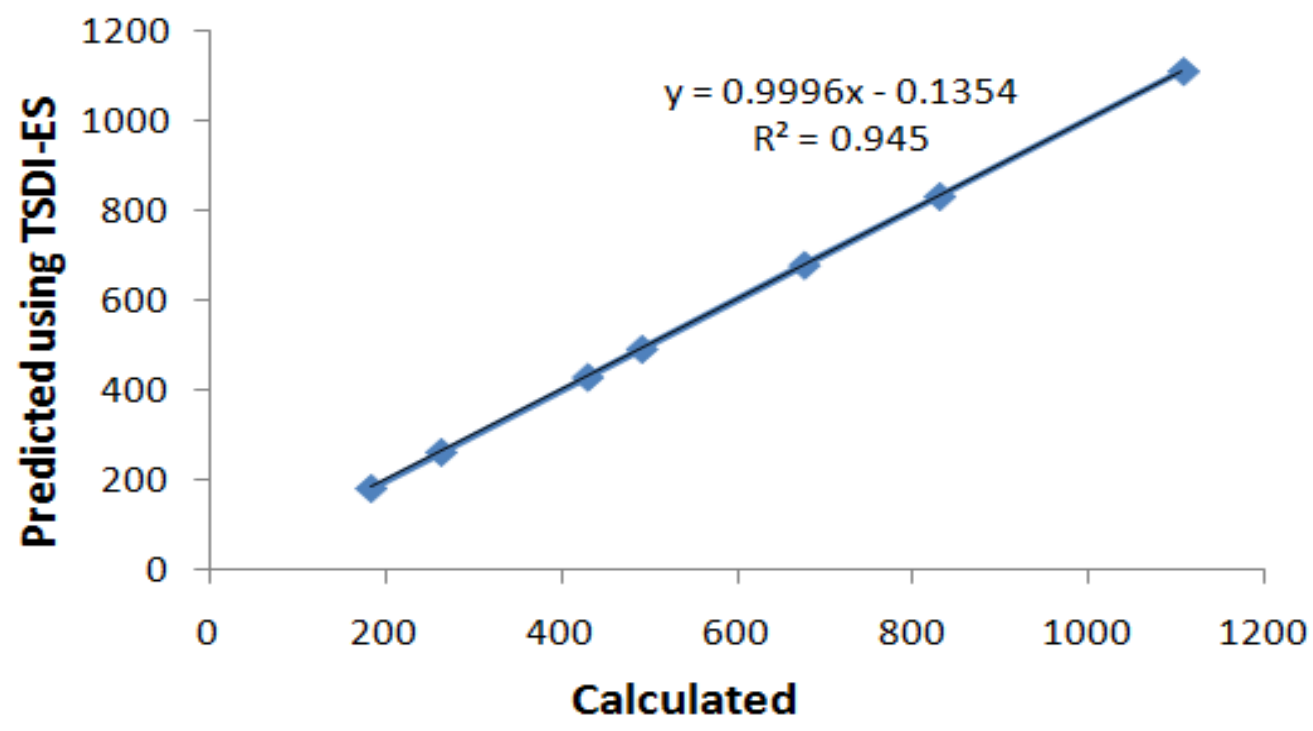

Fig. 5. Calculation of IR using the TSDI-ES Program and manual calculations for sugar beet in Menia region

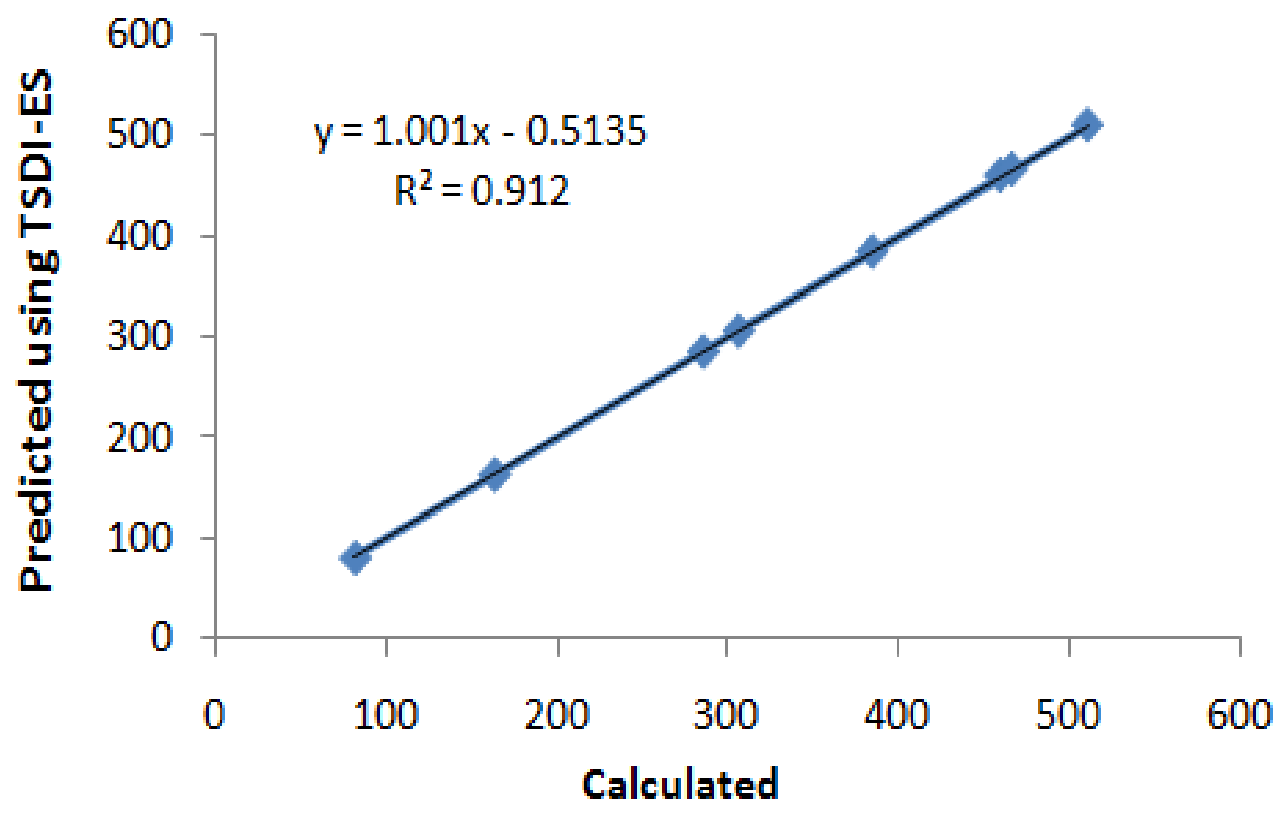

Fig. 6. Calculation of IR using the TSDI-ES Program and manual calculations for olive tree in Farafra region 


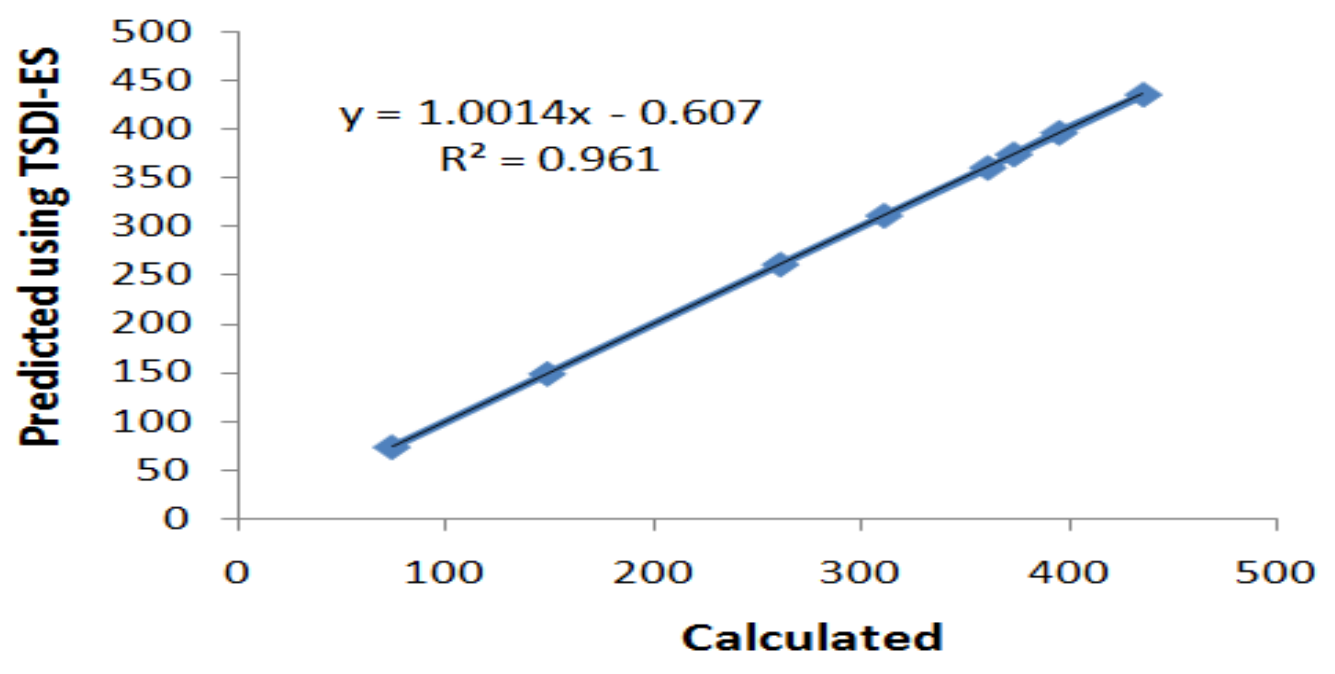

Fig. 7. Calculation of IR using the TSDI-ES Program and manual calculations for palm tree in Farafra region

\section{CONCLUSION}

Expert systems could be an alternative choice for the private sector due to difficulties encountered in finding the expert person at all times and everywhere and high costs of expert persons. Computer programs known as expert systems are believed to be the best fitting method for the solution of complex problems like selection of components of irrigation network. In this study following suggestions could be followed:-

- Better economic decisions will be taken within a short time.

- Likelihood of making mistakes will be eliminated by the use of the program and thus damages that will be caused by mistakes will be prevented.

- With the development of this program, selection of such properties of pumps as cables, electrical organs etc. will be possible and easier.

- This expert system will help pump dealers in selecting the suitable pump from among pump brands with different technical properties.

- The database of this program can be expanded by entering the technical properties of pumps from different firms.

\section{REFERENCES}

Arafa, Y.E. 2004. Selection and design of localized irrigation systems based on expert systems. Ph.D. Thesis., Agric. Eng. Dept., Fac. of Agric., Ain Shams Univ., Cairo, Egypt. 75 p.

Awady, M.N., Sallam, M.F. and Hegazi, A.M. 2002. Expert system approach for selecting mechanized irrigation system for different situations, Misr J. Agric. Eng., 19(2), 285-296.

Kabany, A.G. 2003. Uses of expert systems in agricultural engineering, Unpublished Review Article, Fac. of Agric., Ain Shams Univ., Egypt, $10 \mathrm{p}$.

Mcknion, J.M. and Lemmon, H.E. 1985. Symbolic Computer and All tools for a Cotton Expert System, ASAE, St. Joseph, MI. 85 p.

Patterson, D.W. 2007. Introduction to Artificial Intelligence \& Expert Systems, Prentice-hall, USA., 46 p.

Phocaides, A. 2007. Handbook on Pressurized Irrigation Techniques. Food \& Agriculture Org., pp. 135-143.

Rogers, D.H., Lamm, F.R. and Alam, M. 2003. Subsurface drip irrigation (SDI) components: Minimum requirements. K-State Research and Extension, MF-2576. pp. 550-554.

Selflek, A.Y. and Çarman. K. 2010. A design of an expert system for selecting pumps used in agricultural irrigation. Mathematical and Computational Applications, 15(1), 108-116. 